\title{
Right Aortic Arch
}

National Cancer Institute

\section{Source}

National Cancer Institute. Right Aortic Arch. NCI Thesaurus. Code C103917.

An anatomic abnormality that occurs during embryonic development, in which the aortic arch is right-sided. 